\title{
The Relationship and Predicting Role of Sleep Quality and Sexual Self-Esteem in Secondary Post-Traumatic Stress Disorder among Wives of Veterans
}

Abdoulmalk. L1
${ }^{*}$ Amiri. ${ }^{2}$
Hosseini. SS ${ }^{3}$
Amirpour. ${ }^{4}$
Afshariniya. $\mathrm{K}^{5}$
1- Ph.D. Student of Psychology,
Psychology Department, Faculty
of Humanities, Kermanshah
Branch, Islamic Azad University,
Kermanshah, Iran.
2- ('Corresponding Author)
Ph.D. in Psychology, Assistant
Professor, Psychology
Department, Faculty of
Humanities, Kermanshah
Branch, Islamic Azad University,
Kermanshah, Iran.
Email: Ahasan.amiri@yahoo.com
3- Ph.D. in Psychology, Assistant
Professor, Department
of Psychology, Faculty of
Humanities, Kermanshah
Branch, Islamic Azad University,
Kermanshah, Iran.
4- Ph.D. in Psychology, Assistant
Professor, Psychology
Department, Faculty of
Humanities, Payame-Noor
University Tehran, Tehran, Iran.
5- Ph.D. in Consulting, Assistant
Professor, Psychology
Department, Faculty of
Humanities, Kermanshah
Branch, Islamic Azad University,
Kermanshah, Iran.
Hom

\begin{abstract}
Introduction: Wives of veterans, due to close relationship and taking care of them, are identified as secondary or hidden victims of trauma. This indirect exposure to a stressful event brings psychological consequences for them.
\end{abstract}

Objective: The current study aimed at determining the relationship and predicting role of sleep quality and sexual self-esteem in secondary post-traumatic stress disorder among wives of veterans.

Material and Methods: The present descriptive-analytical study was performed on 152 wives of veterans with secondary post-traumatic stress disorder in Kermanshah Province, Iran in 2019. The subjects were selected by purposive sampling method. To collect data, the Pittsburgh sleep inventory, sexual self-esteem index for womanshort form (validation by Farokhi \& Shareh), and secondary trauma questionnaire (STQ) were used. Data were analyzed by SPSS version 25 using Pearson correlation coefficient and simple linear regression.

Results: According to the findings, the mean \pm standard deviation scores of sleep quality, sexual self-esteem, and secondary traumatic stress disorder were 13.00 \pm 3.88 , $59.11 \pm 11.88$, and $63.43 \pm 10.53$, respectively. The results indicated a positive and significant relationship between low sleep quality and secondary traumatic stress $(\mathrm{r}=$ $0.345, \mathrm{P}<0.01$ ). In addition, there was a significant and negative correlation between sexual self-esteem and secondary traumatic stress $(\mathrm{r}=-0.298, \mathrm{P}<0.01)$. The results of regression analysis showed that $32 \%$ of changes in secondary traumatic disorder can be explained by sleep quality and sexual self-esteem.

Discussion and Conclusion: Given the important role of sleep quality and sexual self-esteem in the predicting secondary traumatic stress disorder, it is suggested to consider the role of these factors in intervention programs for secondary traumatic stress disorder.

Keywords: Secondary Post-traumatic Stress Disorder, Self-Esteem, Sleep, Veterans. 


\section{تعيين رابطه و سهم ييش بينى كنندكى اثر كيفيت خواب و عزت نفس جنسى بر اختلال

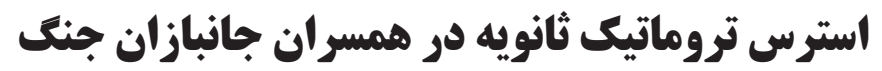

ليلا عبدالملكى"، "حسن اميرى"، سعيده سادات حسينى"، برزو اميريور "، كريم افشارىنياه

جكيده

مقدمه: همسران جانبازان جنگ به واسطه قرابت و يارىرسانى به جانبازان مجروح به عنوان قربانيان ثانويه و ينهان تروما در

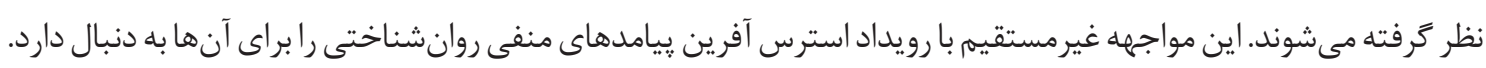

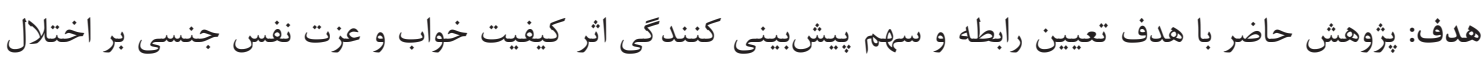

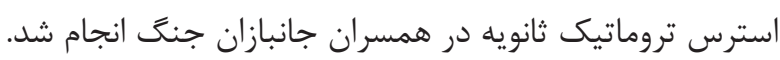

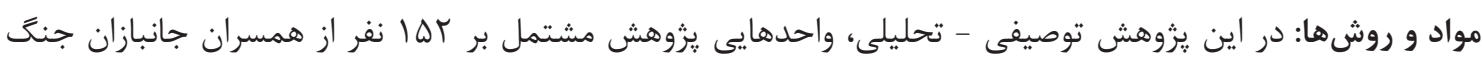

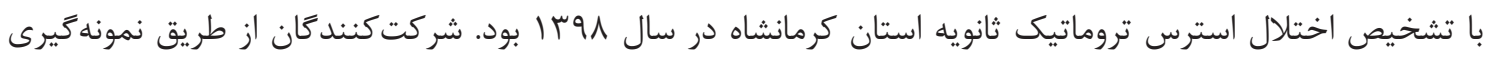

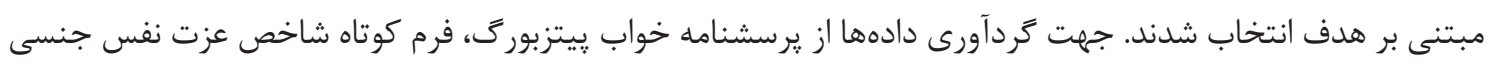

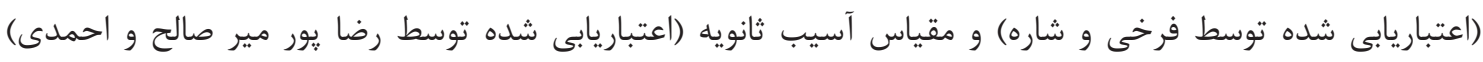

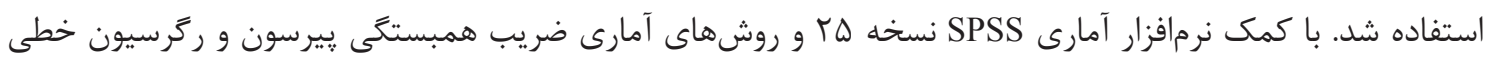

ساده دادهها تحليل شدند.

يافته ها: مطابق با يافتههاى يزوهش، ميانكَين (انحراف معيار) كيفيت خواب، عزت نفس جند جنسى و اختلال استرس تروماتيك

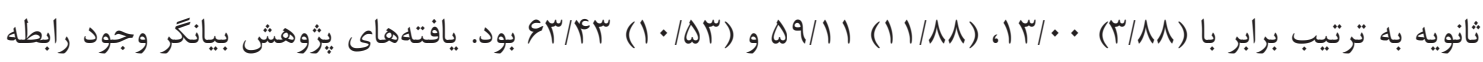

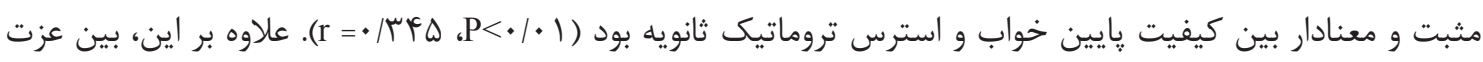

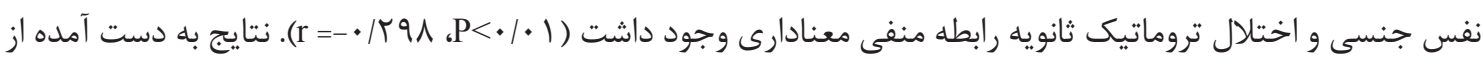

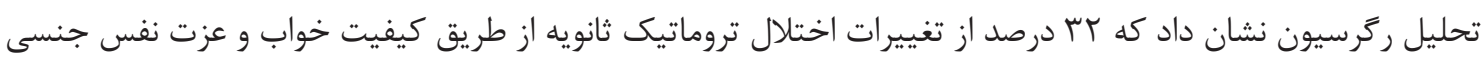
قابل تبيين است. بحث و نتيجه كيرى: با توجه به اهميت كيفيت خواب و عزت نفس جنسى در بيش بينى اختلال استرس تروماتيك ثانويه،

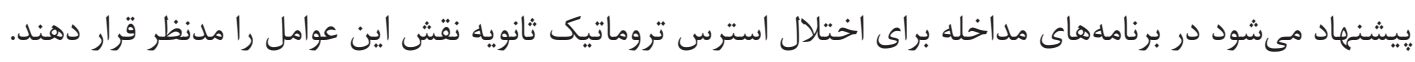

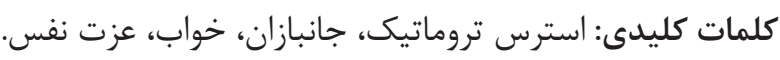

تاريخ دريافت: ت ت

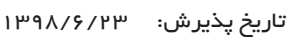

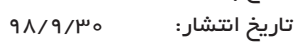

بيمارىها (The ICD-1) Draft) كه توسط سازمان بهداشت مقدمه بر اساس نسخه يِش نويس از يازدهمين طبقهبندى بينالمللى جهانى معرفى شده است اختلال استرس پِس از سانحه، يكى از 
بس از سانحه در موقعيتهاى بالقوه تروماتيك است ( (1). كيفيت

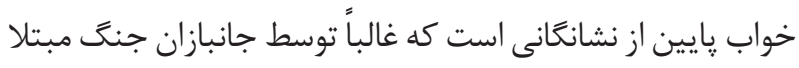

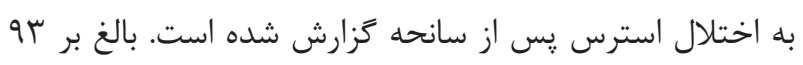

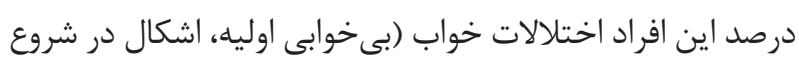

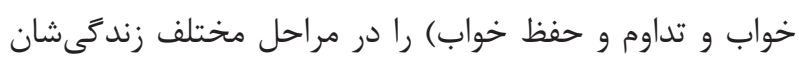

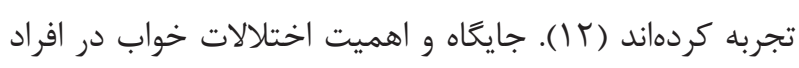
در معرض تروما تا حدودى است كه اصطلاحى با عنوان اختلالات خواب وابسته به تروما Trauma Related Associated Sleep در ييشينه يزوهشهاى اين حوزه مطرح شده

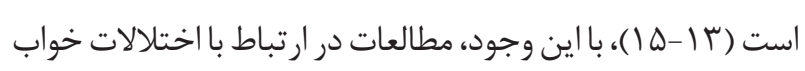

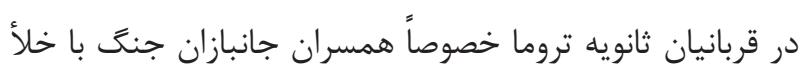
يزوهشى و كمتر مورد توجه يزوهشكَران قراركرفته است.

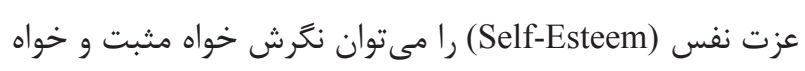
منفى فرد به خويشتن و نوعى از احساس خود ارزشى (Self-Worth)

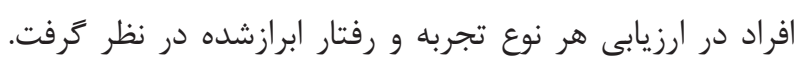

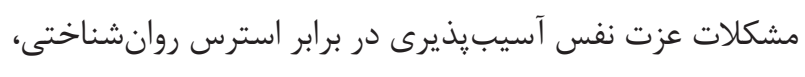

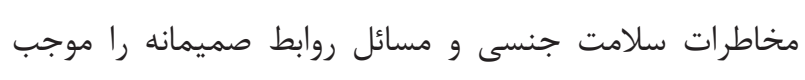
مىشود (91). در حوزه سلامت روان و تندرستى، يك بعد حائز اهميت در عزت نفس كه رفتار جنسى را متأثر كرده و كمتر توجه

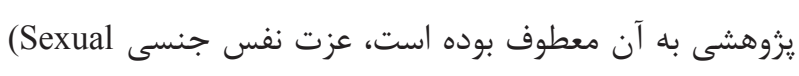
است. عزت نفس جنسى كه به واسطه تصور و ارزش يك شخص به خود بر اساس جذابيتها و قابليتهاى نفي جنسى تعيين مى ارزيابى از افكارشان، احساساتشان و رفتارهاى جنسى اشئ اشاره دارد

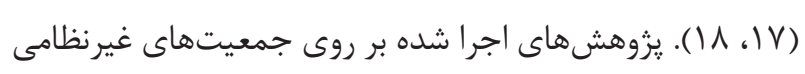

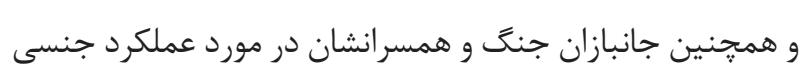

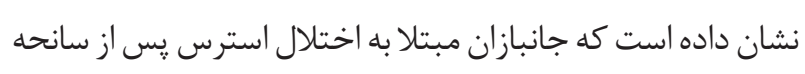

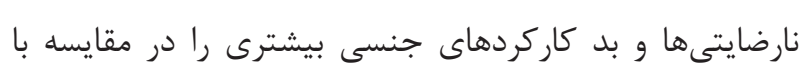

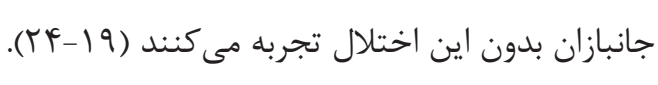

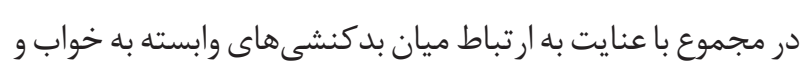

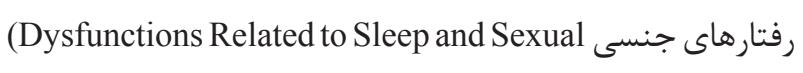
بehavior)

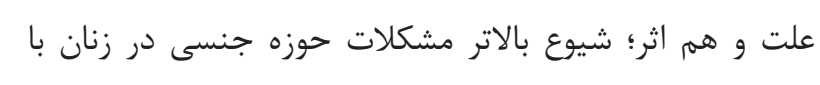

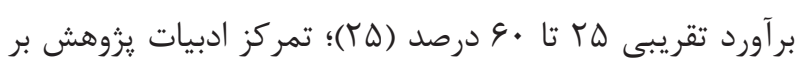

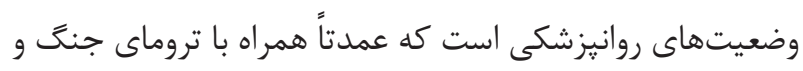

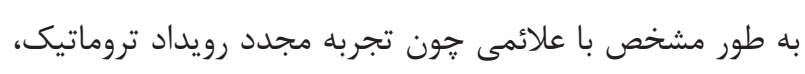

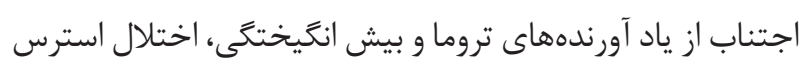

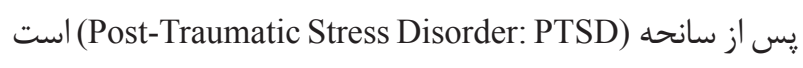

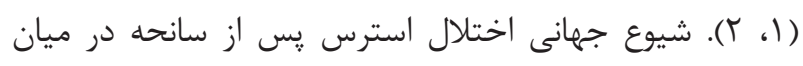

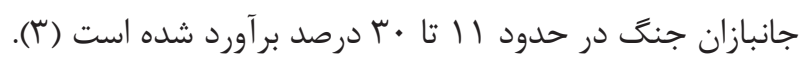

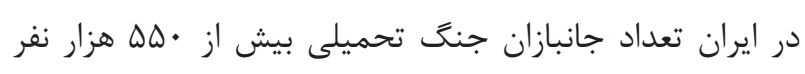

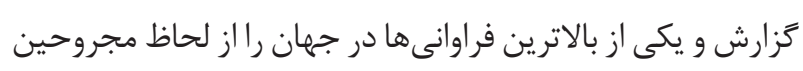

$$
\text { شيميايى دارد (†). (أ). }
$$

از آنجايى كه جانبازان نظامى (Military Veterans) سطوح

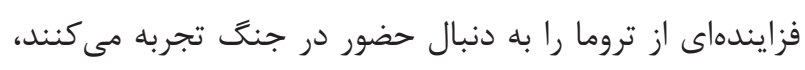

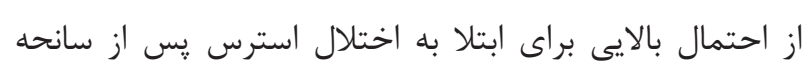

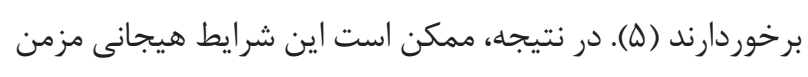

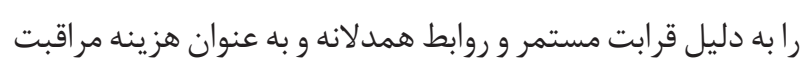
(Cost of Caring)

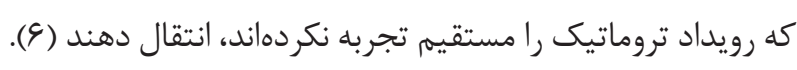

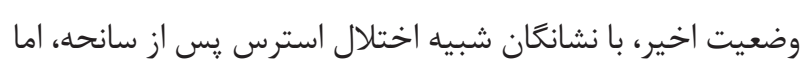

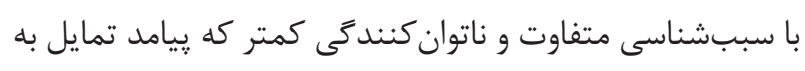

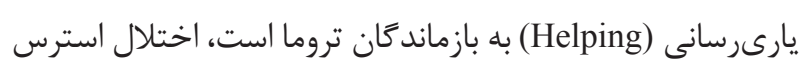

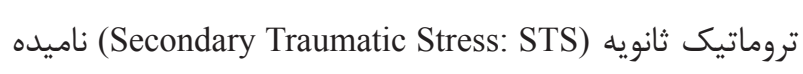

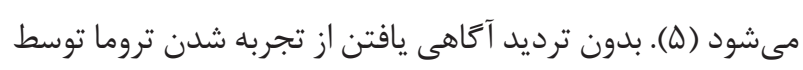

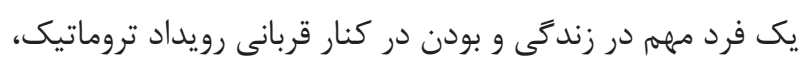
كيفيت زندكى و سلامت روان را كاهش مى دهدد (V، ^). در ايران

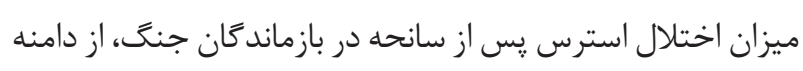
خفيف تا بسيار شديد اله درصد برآورد شده است و اين ميزان

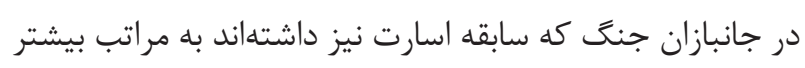

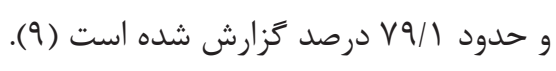

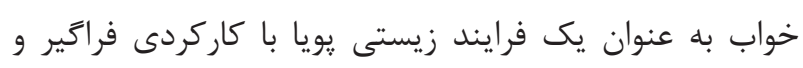

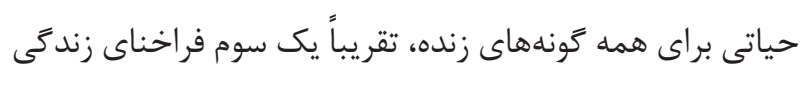
(Life Span) تمام نظامهاى تشخيصى و طبقدبندى اختلالات، مشكلات مرتبط با خواب نه تنها به عنوان يكى از همايندى هاى (Comorbidity)

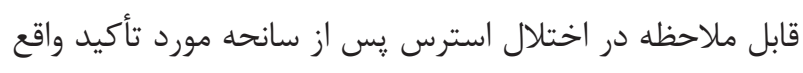

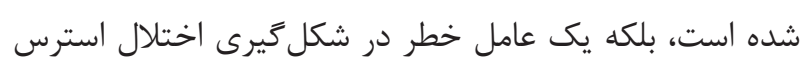


شدنهاى شبانه فرد)، ميزان داروى خوابآور مصرفى و عملكرد

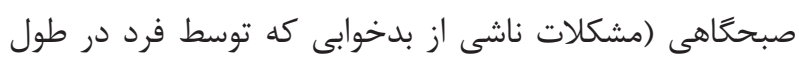

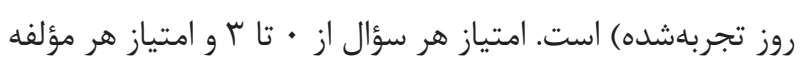

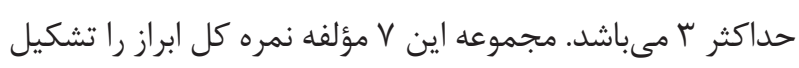

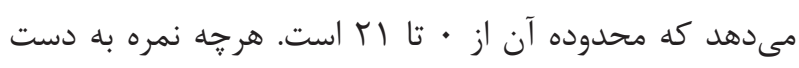

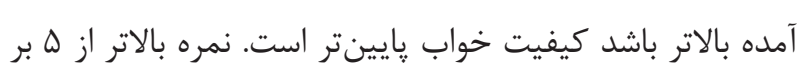

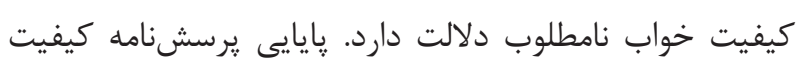

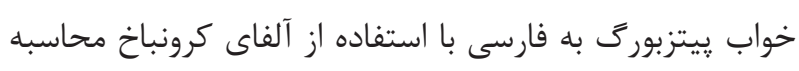

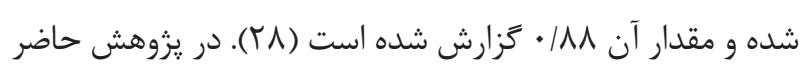

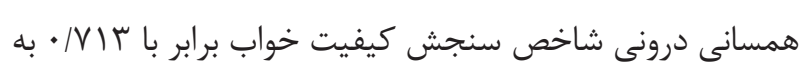

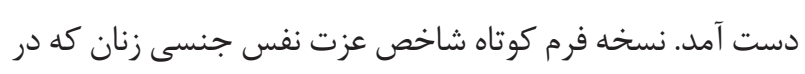

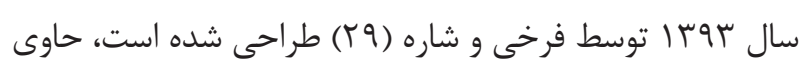

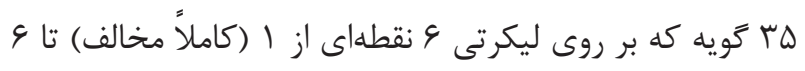

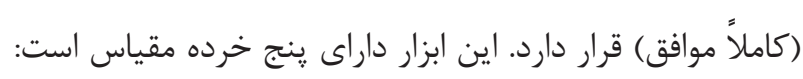

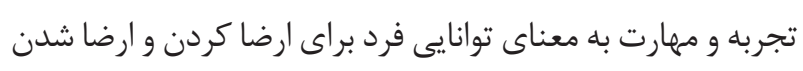
توسط يك شريك جنسى و فرصتها براى دركير شدن در فعاليت

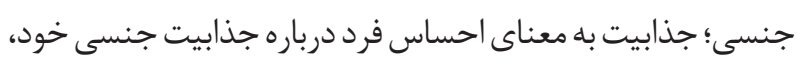

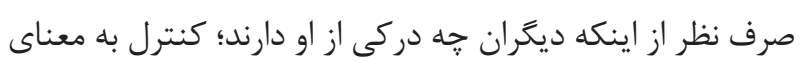

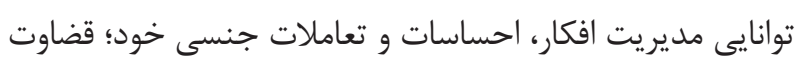
اخلاقى به معناى تناسب افكار، احساسات و رفتار جنسى فرد بات ونسات

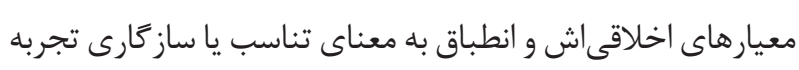

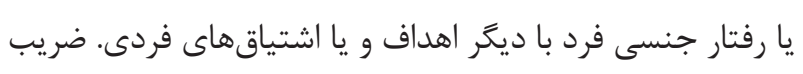

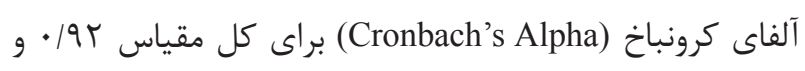
روايى محتوايى آن توسط متخصصان روانشناسى بالينى، درمانكران اختلالات عملكرد جنسى و متخصصان روانسنجى تأييد شد (• (ب). در اين مطالعه توافق درونى برسشنامه با استفاده از روش تصنيف

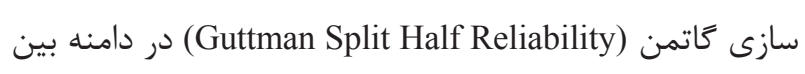

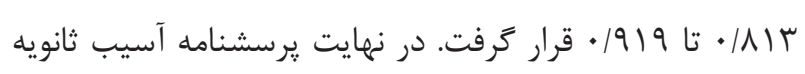

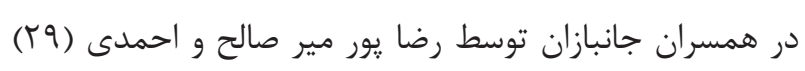
در سال عوبا جهت سنجش اختلال تروماتيك ثانويه همسران

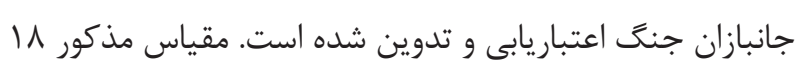

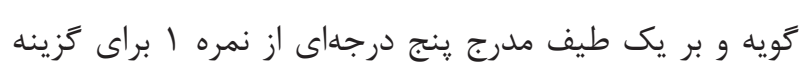

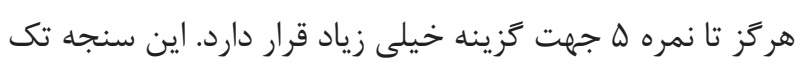
عاملى است و نمره كلى آن نشاندهنده علائم تروماى ثانوى در
بازماندكان اوليه رويدادهاى تروماتيك تا ثانويه و غفلت از خانواده

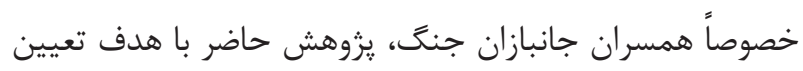

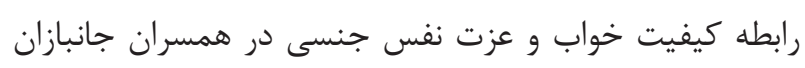

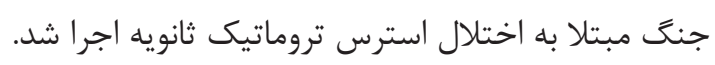

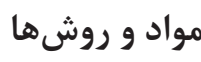

يزوهش حاضر توصيفى - تحليلى مىباشد كه به صورت مقطعى رونى

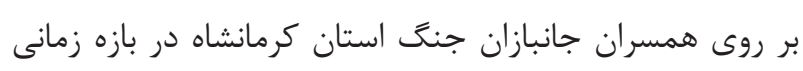

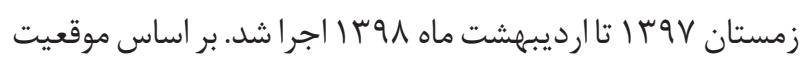
جغرافيايى، واحدهاى يزوهش با عنايت به كفايت حجم نمونه

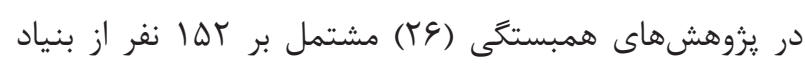
شهيد مركز استان و شهرهاى شرقى (هرسين، صحنه و كنكاور)

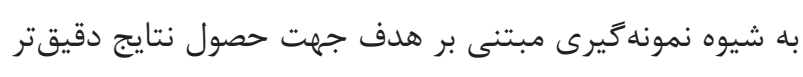

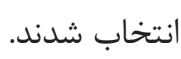

ملاك هاى ورود به يزوهش عبارت بودند از: به دليل مشخص نبودن

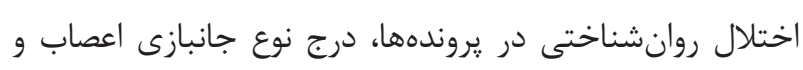

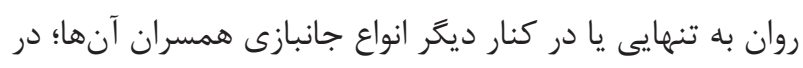

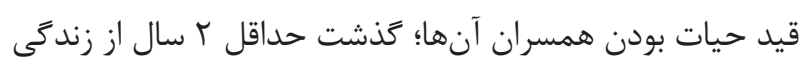

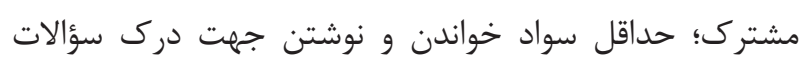

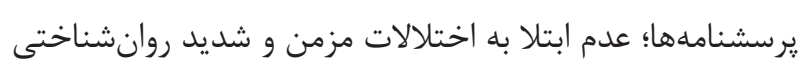

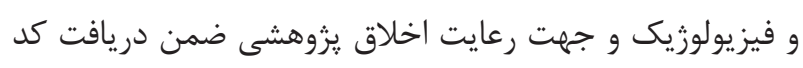

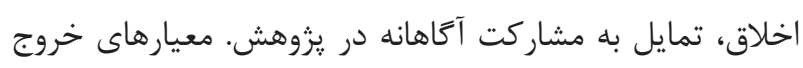

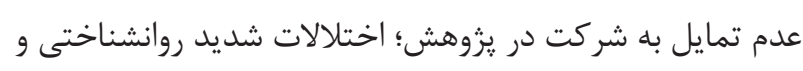
در قيد حيات نبودن همسران.

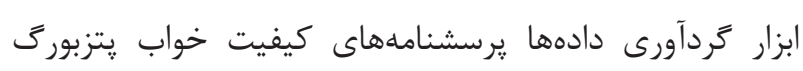
(Pittsburgh Sleep Quality Index) نفس جنسى زنان (Sexual Self-Esteem Index): و وبرسشنامه

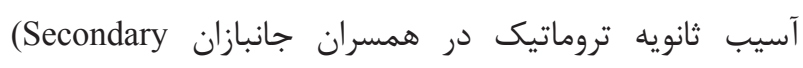
Trauma Questionnaire in Warfare -STQ) كيفيت خواب كه در سال 1919 توسط بويس و همكاران (TV)

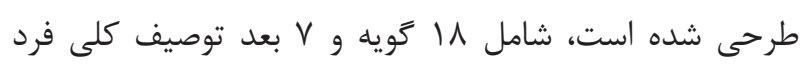
از كيفيت خواب، تأخير در به خواب رفتن، طول مدت خدو خواب مفيد، كفايت خواب (نسبت طول مدت خواب مفيد باخير در به كل زول زمان

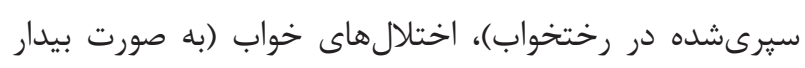


بودند. آمارههاى توصيفى براى متغيرهاى يزوهش كزارش شده است (جدول ()).

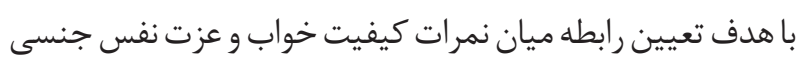

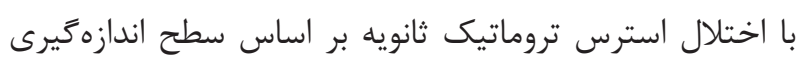

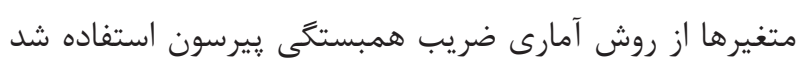

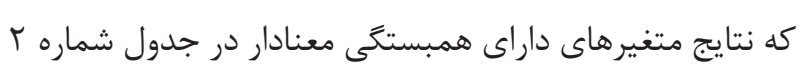

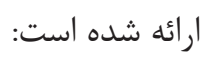

بر اساس نتايج ضر يب همبستخى ييرسون در جدول شماره ץ - بين

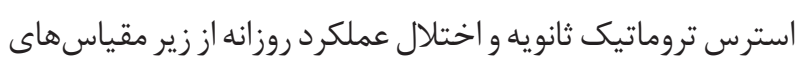

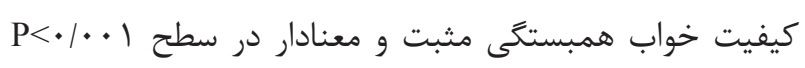

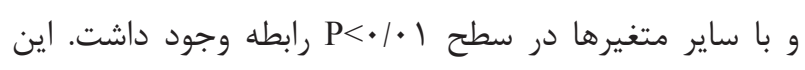

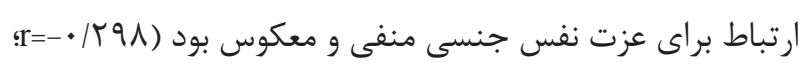

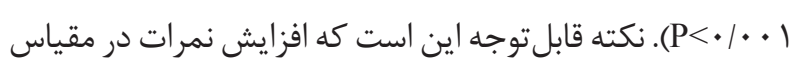

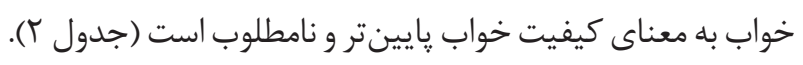
جهت تعيين سهم متغيرهاى ييش بين در تبيين استرس

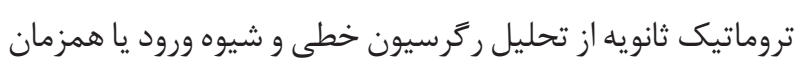
استفاده شد. قبل از اجراى اين روش آمارى

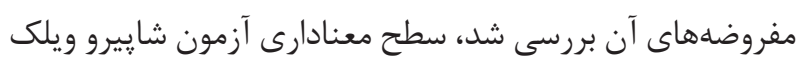
د در متغير ها بالاتر از لهدم يعنى ه ه • (Shapiro-Wilk)

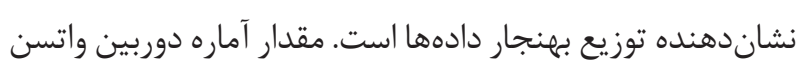

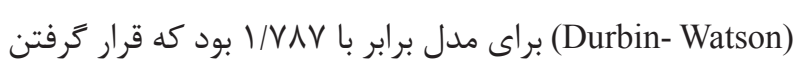
اين شاخص آمارى بين ا تا F دلالت بر مستقل بودن باقيماندهها

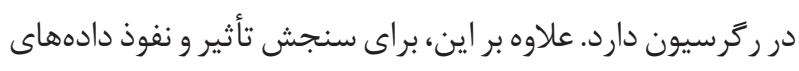

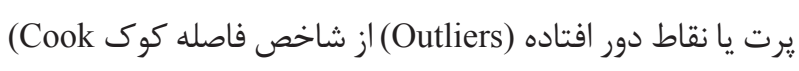

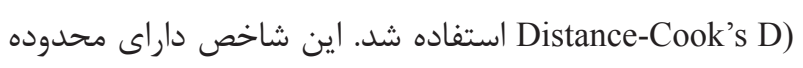

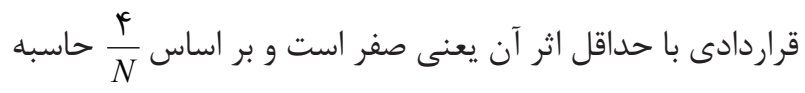

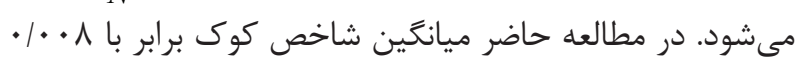

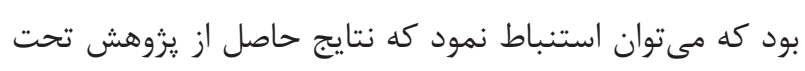

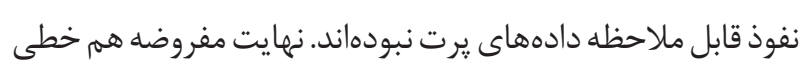
بودن (Collinearity) با دو شاخص ضريب تتحمل (Olerance) و

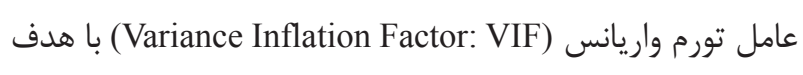
تشخيص مستقل بودن متغيرهاى ييش بين نشان داد كه بين

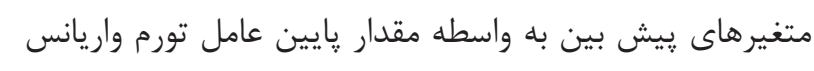
و فاصله خوب ضريب تحمل از · و نزديكى به إئه (با ميانكين
افراد است. حداقل نمره 11 و حداكثر آن •ج و نقطه برش نمره هَr جهت تشخيص كذارى اختلال مطرح شده است. سازندكان

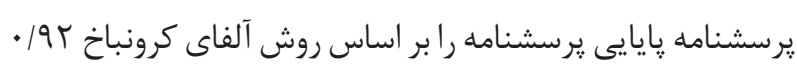
كزارش كردهاند. در ارتباط با روايى محتوا (Content Validity) با استفاده از روش والتز و باسل (Waltz \& Bausell) و بر بر اساس رداس

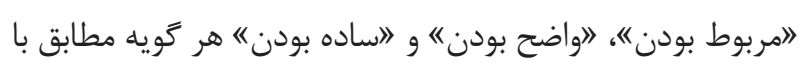

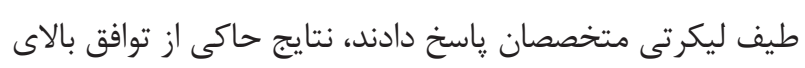

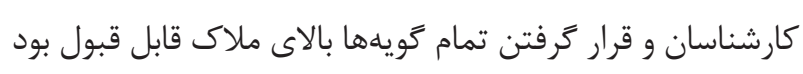

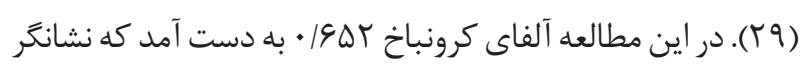
يايايى مقياس حاضر در اين يزوهش مى بـاشد.

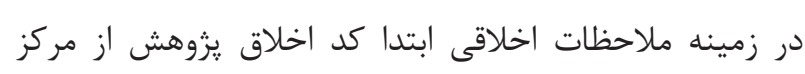

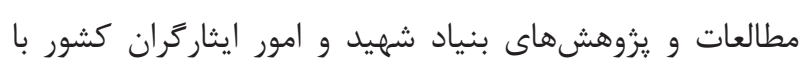

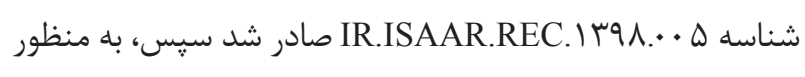
حفظ حريمم رازدارى ضمن تشريح اهداف يزوهش از درج مشخصات

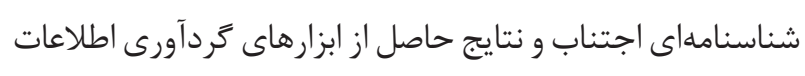
به دنبال درخواست برخى از شركت كنند

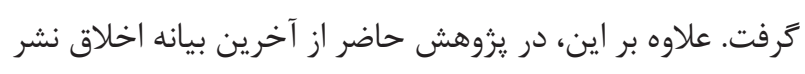
(COPE)

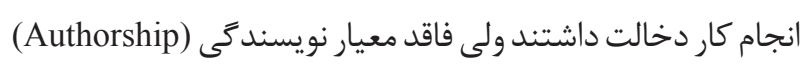
مىباشند در بخش سياسگزارى نام برده شده است؛ عدم ارسال

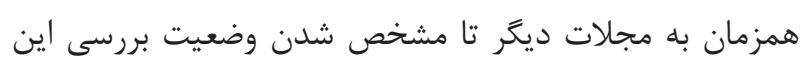

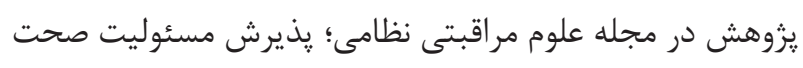

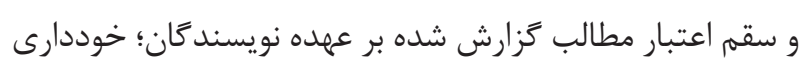

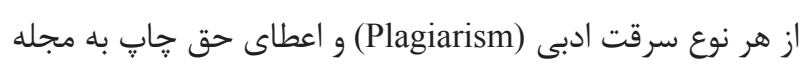
مذكور و توجه به تعارض منافع احتمالى از ديگر موارد تطبيق

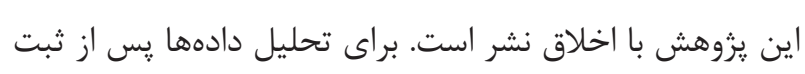

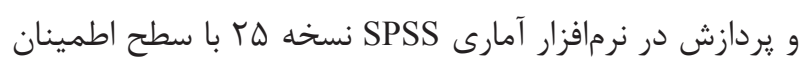

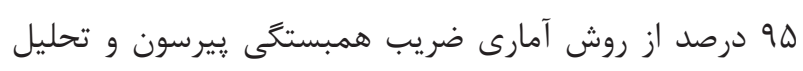
ركرسيون استفاده شده است.

\section{يافتهها}

در مطالعه حاضر هr ا نفر شركت داشتند. اكثريت واحدهاى مورد يزوهش، از لحاظ سطح تحصيلات داراى مدرك ابتدايى؛ اب نفر

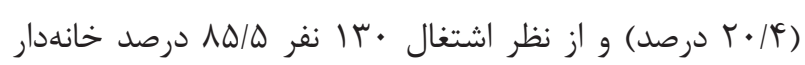


جدول ا - آمارههاى توصيفى متغيرهاى يزوهش (N=I Tr)

\begin{tabular}{|c|c|c|c|}
\hline حداكثر & حداقل & (انحراف معيار) ميانگين & متغير \\
\hline 99 & tr & 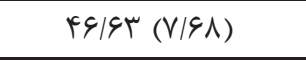 & سن (سال) \\
\hline V & $\cdot$ & $r / \mathcal{F}(1 / \mathbb{F} \Delta)$ & تعداد فرزندان (نفر) \\
\hline$\Delta r$ & r & $r 9 / 0 \cdot(9 / 09)$ & مدت ازدواج (سال) \\
\hline$\wedge \Delta$ & rV & QT/FT $(1 \cdot \mid \Delta \Delta)$ & استرس تروماتيك ثانويه \\
\hline $1 \pi$ & $i d$ & $\Delta 9 / 11(11 / / \Lambda)$ & عزت نفس جنسى \\
\hline ro & 4 & $11 / 9 \cdot(1 / 11)$ & تجربه و مهارت \\
\hline r. & V & $1 \% / 9 V(\Pi / 11)$ & جذابيت \\
\hline rᄉ & $\Lambda$ & $11 / 9 \mathbb{F}(\Psi / \mathcal{F} \wedge)$ & كنترل \\
\hline rq & 11 & $19 / 90(1 / 99)$ & قضاوت اخلاقى \\
\hline re & V & $11 / \cdot 1(T / 91)$ & انطباق \\
\hline r & $\cdot$ & $1 / 94(\cdot / 99)$ & كيفيت ذهنى خواب \\
\hline r & $\cdot$ & $1 / 19(\cdot / 94)$ & تأخير در بخواب رفتن \\
\hline r & · & $r / T \cdot(\cdot / 9 \Delta)$ & مدت زمان خواب \\
\hline$r$ & · & T/TG (.|AG) & كفايت خواب \\
\hline r & . & $I / \wedge V(1 / / \Delta)$ & اختلالات خواب \\
\hline$r$ & $\cdot$ & $I / V \wedge(|/| F)$ & استفاده از داروهاى خوابآ ور \\
\hline r & - & $1 / 4 F(1 / 19)$ & اختلال در عملكرد روزانه \\
\hline$r \cdot$ & r & $\mid r / \cdots(r / \Lambda \Lambda)$ & نمره كلى آزمون كيفيت خواب ريتزبورى \\
\hline
\end{tabular}

جدول r - نتايج ضريب همبستخى ييرسون ميان استرس تروماتيك ثانويه با متغيرهاى ييش بين بزوهش

\begin{tabular}{|c|c|c|c|c|c|c|c|}
\hline اختلال در عملكرد & خواب آستاده آ داروهاى & خواب اختلات & كيفيت ذهنى & نمره كلى كيفيت & عزت نفس & طول مدت ازدواج & متغير \\
\hline $\mathrm{r}=\cdot / 1 \wedge$. & $r=\cdot / \mu \varphi d$ & $r=\cdot / 4 \Delta q$ & $\mathrm{r}=\cdot / \mu F F$ & $r=\cdot / \mu \varphi d$ & $\mathrm{r}=-\cdot / r 91$ & r= & استرس \\
\hline $\mathrm{P}=\cdot / \cdot r V^{*}$ & $\mathrm{P}=\cdot / \cdot \cdots$ & $\mathrm{P}=\cdot / \cdots$ & $\mathrm{P}=\cdot / \cdots$ & $\mathrm{P}=\cdot / \cdot \cdots$ & $\mathrm{P}<\cdot / \cdots$ & $\mathrm{P}=\cdot / \cdot r$ & تروماتيك ثانويه \\
\hline
\end{tabular}

علاوه بر اين شدت تأثير خالص (استاندارد) و ارزش پيشبينى كنندگى عزت نفس جنسى بر استرس تروماتيك ثانويه برابر با 1/ • •--است، با توجه به وجود دو متغير مستقل در يزوهش مقدار ضريب همبستخى (R= (RSV) با بتا برابر نيست بلكه بين دو مقدار

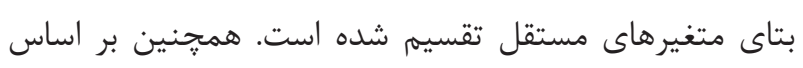
سطح معنى دارى مشاهده شده در زير مقياس اختلال در عملكرد

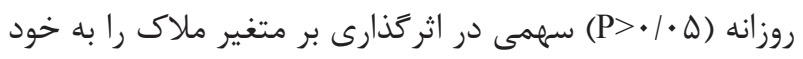

اختصاص نداده است (جدول س). معادله رگرسيون خطى:ضرايب رگرسيونى استاندارد نشده يا همان شيب خط (B) در ززارش معادله ركرسيون خطى ززارش مى شود

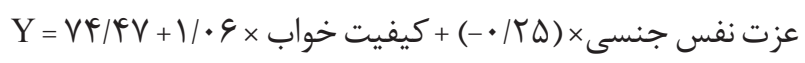

تقريبى VV9/ • براى متغيرهاى مستقل) همبستخى بالايى وجود ندارد. آزمون تحليل واريانس (NOVA) معنادارى رگرسيون براى

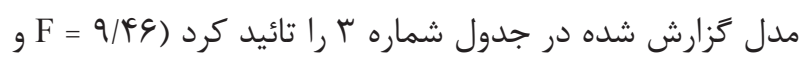

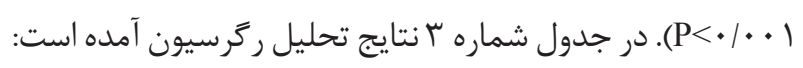
نتايج حاصل از رگرسيون در جدول شماره ب نشان مىدهد كه نسبتى از واريانس استرس تروماتيك ثانويه كه توسط كيفيت خواب و عزت نفس جنسى تبيين مىشود تقريباً بس درصد است

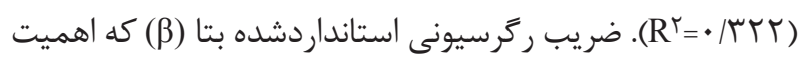
نسبى هر متغير مستقل را مشخص مى كند، حاكى از آن است

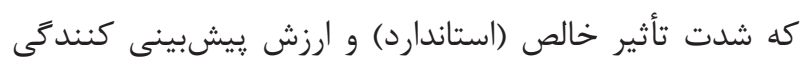
كيفيت خواب بر استرس تروماتيك ثانويه برابر با وس/ • است. 


\begin{tabular}{|c|c|c|c|c|}
\hline & Adjusted $\mathbf{R}^{r}$ & $\mathbf{R}^{r}$ & $\mathbf{R}$ & مدل \\
\hline & $\cdot / r \wedge 9$ & שTTK & $\cdot \mid \Delta S V$ & 1 \\
\hline $\mathrm{P}$ & $\mathrm{T}$ & $\beta$ & $\mathrm{B}$ & متغيرهاى پيش بين \\
\hline$\cdot 1 \cdot \cdots$ & $11 / 9 r$ & & $V F / F V$ & مقدار ثابت \\
\hline$\cdot / \mu k \cdot$ & .190 & $\cdot 1 \cdot V$ & $\cdot 1 \cdot V$ & طول مدت ازدواج \\
\hline$\cdot 1 \cdots$ & -r/ar & $-\cdot / 4 \Lambda$ & $-\cdot / T \Delta$ & عزت نفس جنسى \\
\hline$\cdot 1 \cdot 1 \mathrm{~V}$ & $r|q|$ & $\cdot / \mu q$ & $1 / \cdot 9$ & نمره كلى كيفيت خواب \\
\hline$\cdot 1 \cdot r \Lambda$ & $r / 4)$ & $\cdot / 4$ & $r / I V$ & كيفيت ذهنى خواب \\
\hline$\cdot 1 \cdots$ & $4 / 19$ & $\cdot / 4$ & r/99 & اختلالات خواب \\
\hline$\cdot 1 \cdot r t$ & $r / T)$ & r & $r / 19$ & استفاده از داروهاى خوابآور \\
\hline$\cdot / T \Delta \Lambda$ & 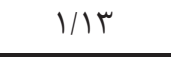 & $\cdot 11 \cdot$ & $\cdot 194$ & اختلال در عملكرد روزانه \\
\hline
\end{tabular}

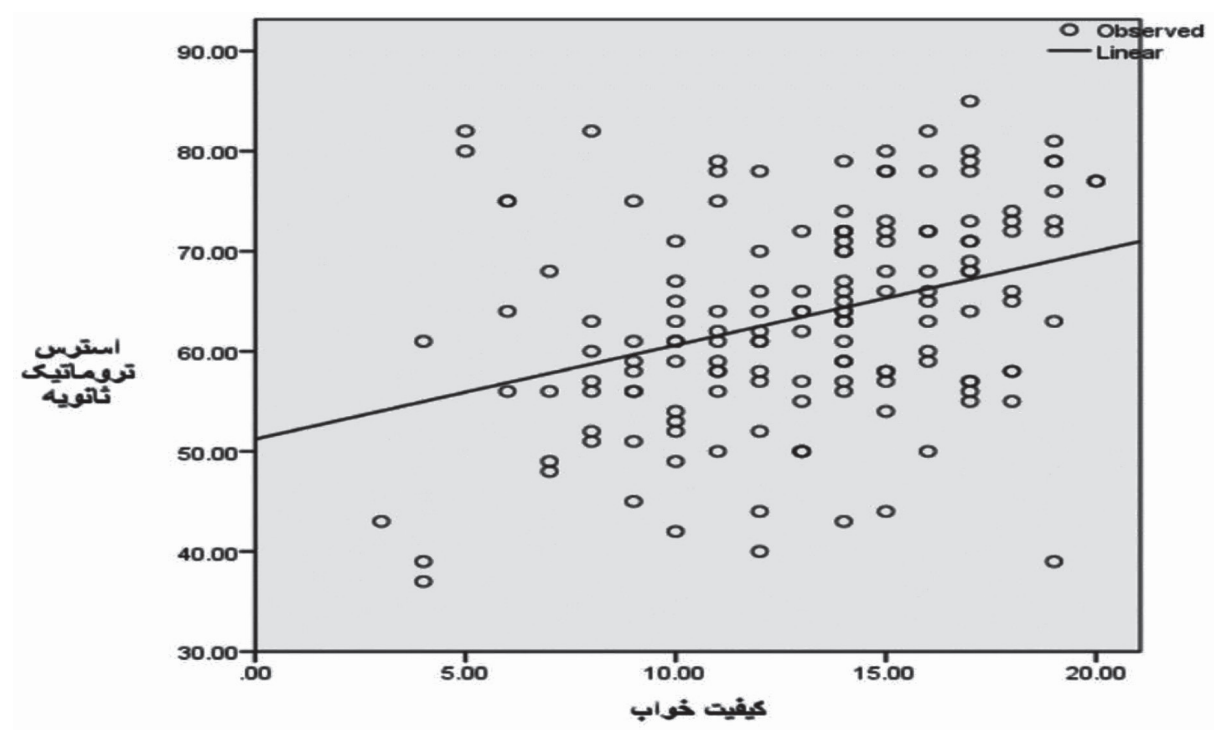

شكل ا - نمودار ركر سيون رابطه كيفيت خواب و استرس تروماتيك ثانويه

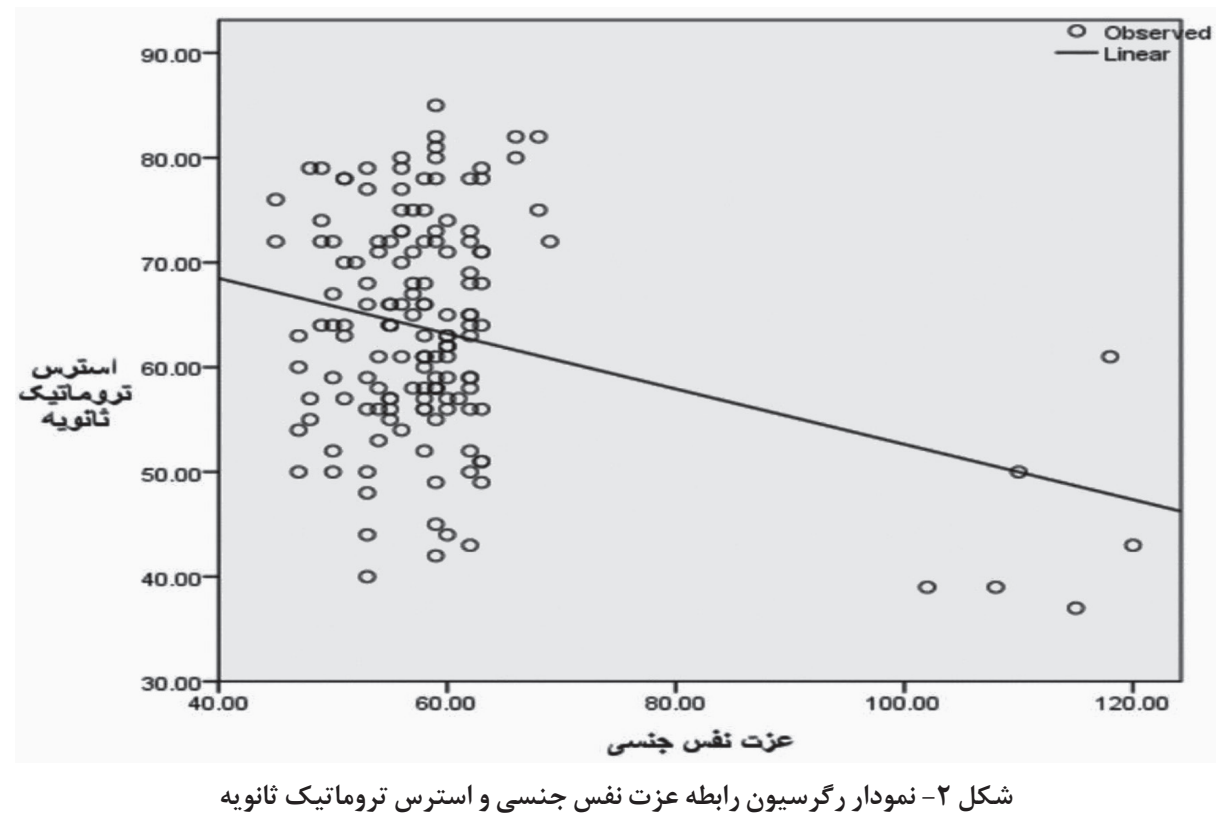


و همكاران استناد نمود. در اين مطالعه انجام شده بر (Sopp)

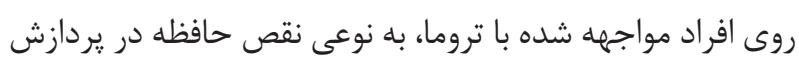

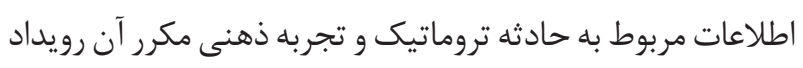

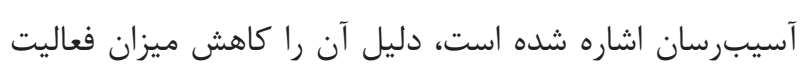

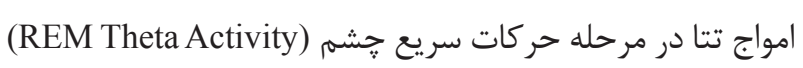
در خواب كزارش كردهاند (ب).

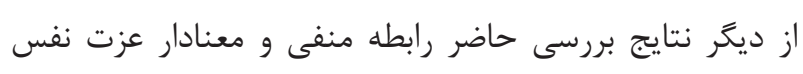
جنسى و سهمم تأثير كذار با بتاى منفى و معنادار آن با اختلال

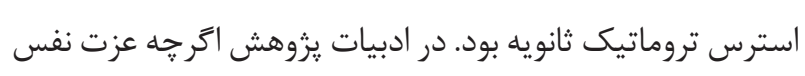
جنسى به عنوان يك بعد از رفتار جنسى در مبتلايان به اختلال

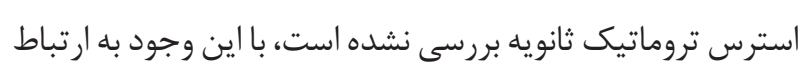

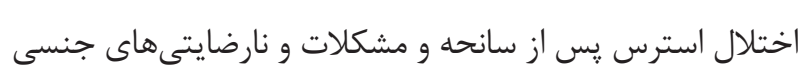

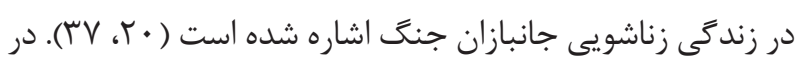
تبيين اين ارتباط بايد خاطرنشان ساخت كه عزت نفس مثبت ديت در

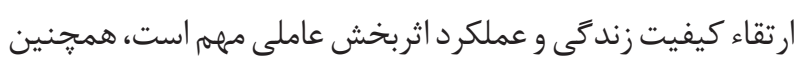
زندَى جنسى يك شخص ابعاد مختلف تندرستى، بهزيستى و

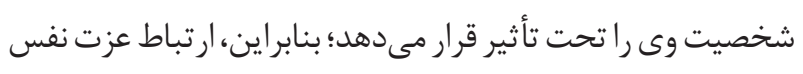

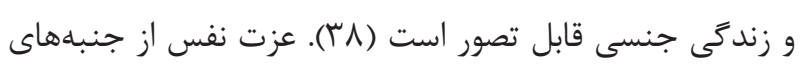

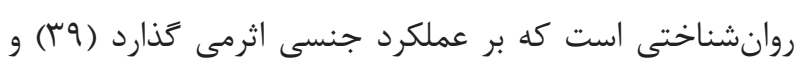

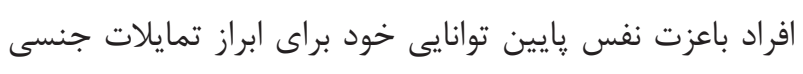

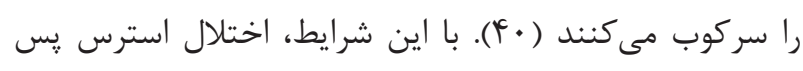

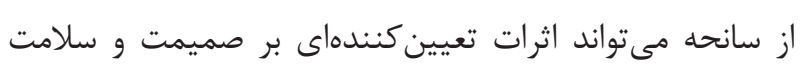

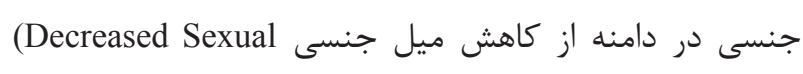

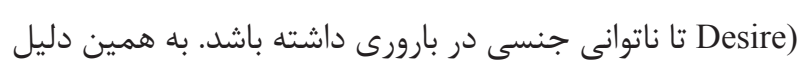

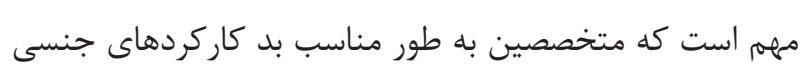

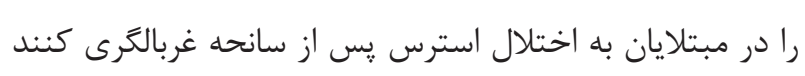

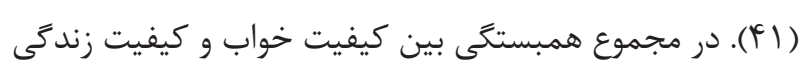
جنسى زنان براى ساير يزوهشكران در ديخر نمونههاى آمارى مثلاً

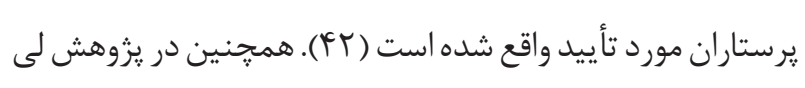

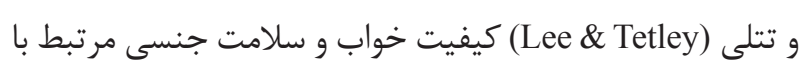
يكديكر عنوان شده است به نحوى كه حتى كيفيت خواب پإيينتر

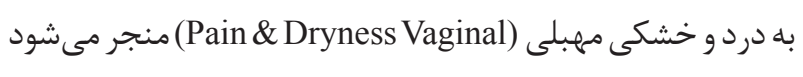

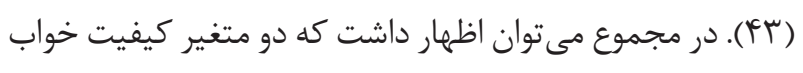

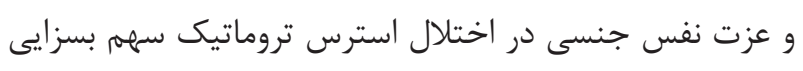

\section{بحث و نتيجه كيرى}

در راستاى بررسى عوامل مرتبط با اختلال تروماتيك ثانويه،

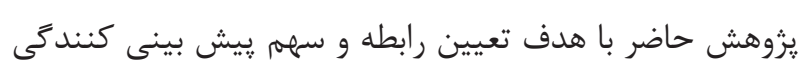

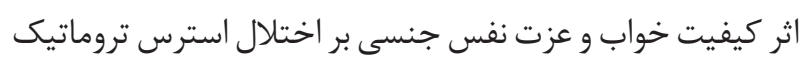

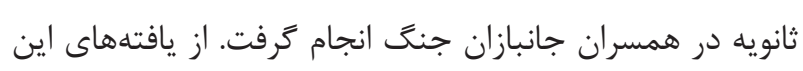
مطالعه رابطه مثبت و معنادار بين كيفيت خواب (نمرات بالاتر به

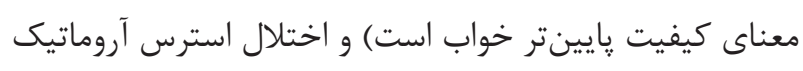

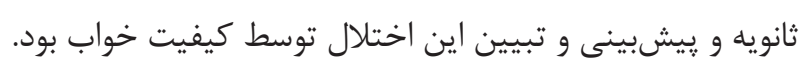

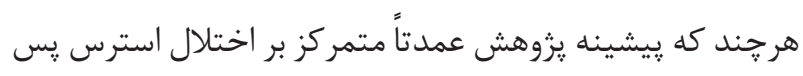

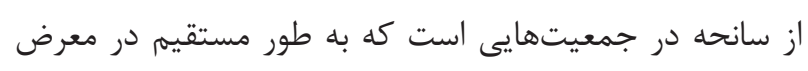

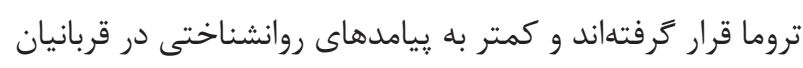

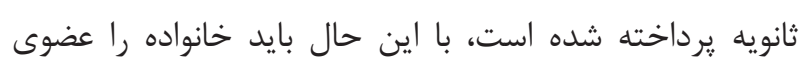

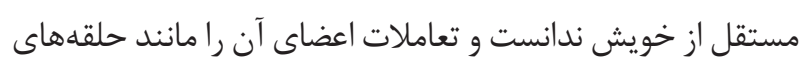
زنجير وابسته به هم دانست؛ بنابراين همه اعضاى خانواده جانباز

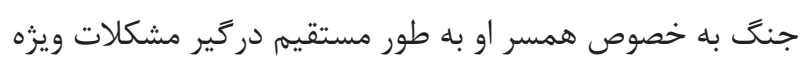

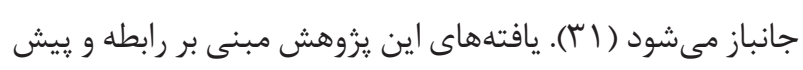

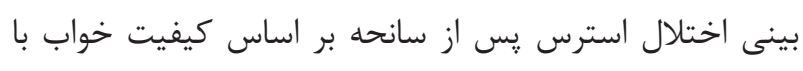

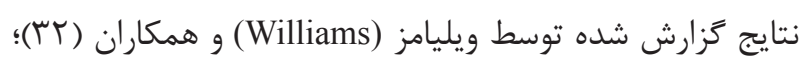
زرومن (Germain) و همكاران (سب)، ميسلويتس (Mysliwiec)

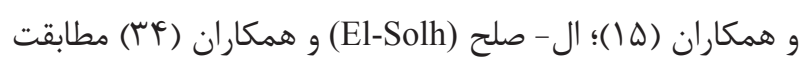

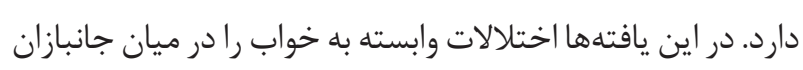

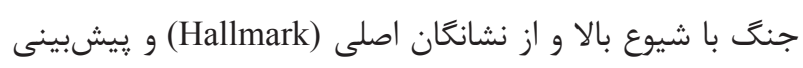

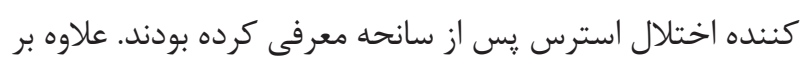

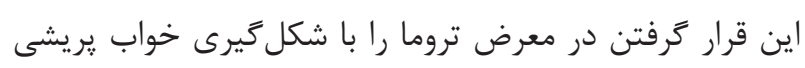

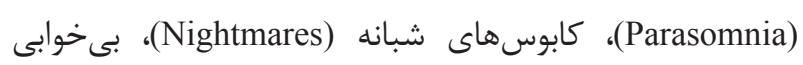

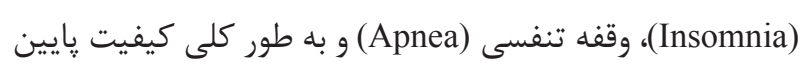
خواب مرتبط دانسته بودند. در تبيين اين يافتهها مىتوان اظهار داشت كه خواب به واسطه به بودند نقش كليدى كه در سلامت روانى، بدنى و هيجانى انسانها دارد،

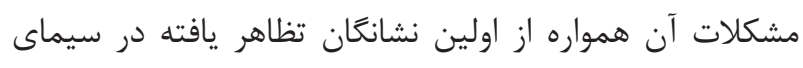

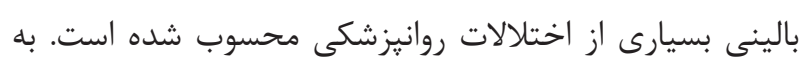

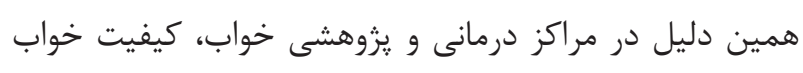

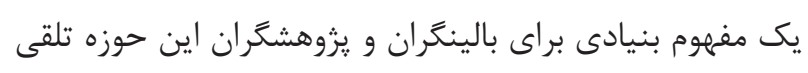

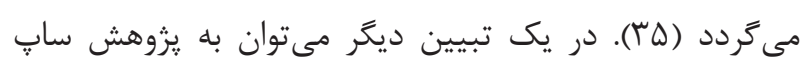




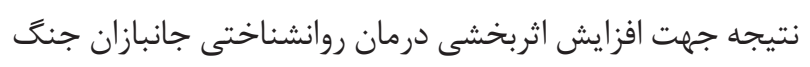

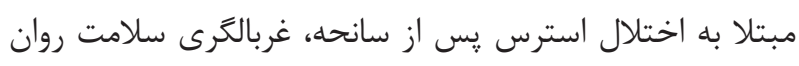$$
\text { همسران و فرزندان جانباز يك ضرورت است. }
$$

\section{تشكر و قدردانى}

مقاله حاضر بر كرفته از رساله دوره دكتراى روانشناسى دانشعاه

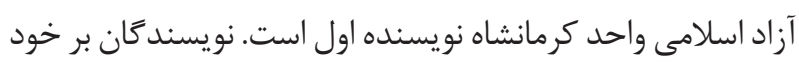
مى دانند كه از حضور شركت كنند يزوهشى مستقر در بنياد شهيد سه شهر تشكيل دهنده نمونه آمارى

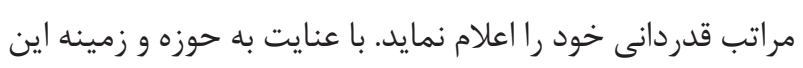
مطالعه، رساله حاضر در كميته امور يزوهشى بنياد شهيد و امور

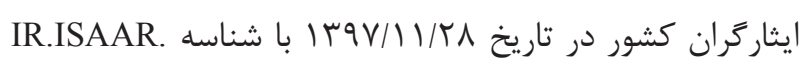

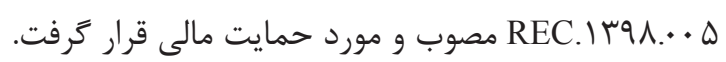

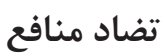

بدين وسيله نويسندًان مقاله اظهار مىنمايند كه هيجَّونه تضاد

$$
\text { منافعى در خصوص يزوهش حاضر وجود ندارد. }
$$

\section{References}

1- Grossman ES, Hoffman YSG, Shrira A, Kedar M, Ben-Ezra M, Dinnayi M, et al. Preliminary evidence linking complex-PTSD to insomnia in a sample of Yazidi genocide survivors. Psychiatry Res. 2019;271:161-6. http://dx.doi.org/10.1016/j.psychres.2018.11.044 www.ncbi.nlm.nih.gov/pubmed/30481693

2- Barbano AC, van der Mei WF, Bryant RA, Delahanty DL, deRoonCassini TA, Matsuoka YJ, et al. Clinical implications of the proposed ICD-11 PTSD diagnostic criteria. Psychol Med. 2019;49(3):48390. http://dx.doi.org/10.1017/S0033291718001101 www.ncbi. nlm.nih.gov/pubmed/29754591

3- Seadatee Shamir A, Sanee'I Hamzanlouyi R. Relationship between Intelligence Beliefs and Achievement Motivation with Self-regulated Learning in Students with Veteran Parents Injured More than 40\%. Iranian J War \& Public Health. 2017;9(4):205-10. http://dx.doi.org/10.29252/acadpub.ijwph.9.4.205

4- Collins T. Military Parent's PTSD and Children's Mental Health: A Scoping Review. The Qualitative Report. 2018;23(5):1237-55.

5- Greinacher A, Derezza-Greeven C, Herzog W, Nikendei C. Secondary traumatization in first responders: a systematic review. Eur J Psychotraumatol. 2019;10(1):1562840. http://dx.doi.or g/10.1080/20008198.2018.1562840 www.ncbi.nlm.nih.gov/ pubmed/30719236
دارند و هر كدام مىتوانند ميزانى از واريانس اختلال استرس تروماتيك را تبيين كنند.

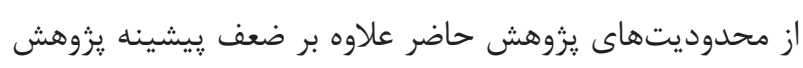

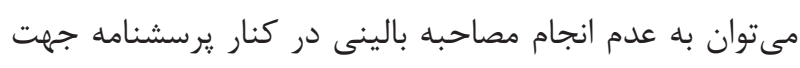
تشخيص دقيقتر اختلال استرس تروماتيك ثانويه اشاره نمود.

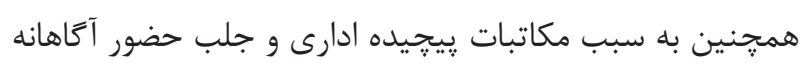
شركت كنند

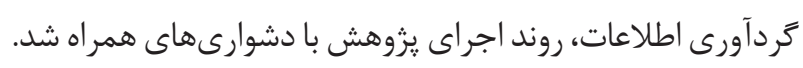
در نهايت در يزوهشهاى با ماهيت همبستخى امكان برداشت يك إنى

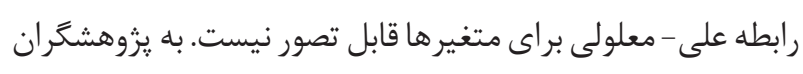

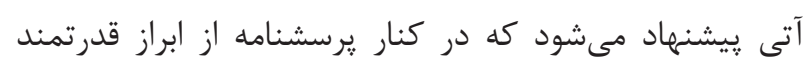

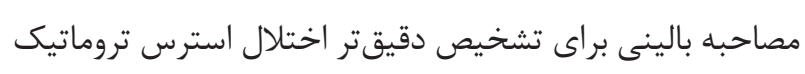

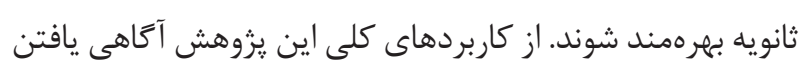

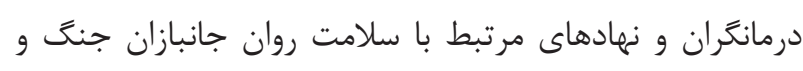

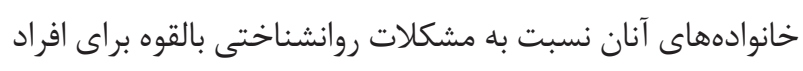

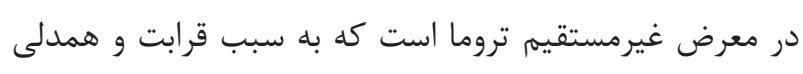

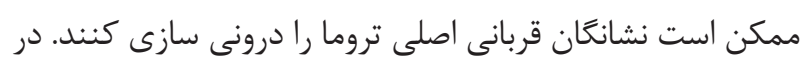

6- Akbari B, Ghasemi Jobaneh R, Asadiparvar M. Role of Coping Strategies with Stress in Resiliency and Quality of Life of Female Adolescents with Veteran Father. Iranian J of War \& Public Health. 2017;9(4):199-203. http://dx.doi.org/10.29252/acadpub. ijwph.9.4.199

7- Toomey R, Alpern R, Reda DJ, Baker DG, Vasterling JJ, Blanchard $\mathrm{M}$, et al. Mental health in spouses of U.S. Gulf War veterans. Psychiatry Res. 2019;275:287-95. http://dx.doi.org/10.1016/j. psychres.2019.03.043 www.ncbi.nlm.nih.gov/pubmed/30953873

8- Kamalmanesh A, Maredpour A. Evaluation of Post-Traumatic Stress Disorder among War Survivors. Health Research J. 2017;2(2):87-98. http://dx.doi.org/10.18869/acadpub. hrjbaq.2.2.87

9- M KP, Latreille V. Sleep Disorders. Am J Med. 2019;132(3):2929. http://dx.doi.org/10.1016/j.amjmed.2018.09.021 www.ncbi. nlm.nih.gov/pubmed/30292731

10- Milanak ME, Zuromski KL, Cero I, Wilkerson AK, Resnick HS, Kilpatrick DG. Traumatic Event Exposure, Posttraumatic Stress Disorder, and Sleep Disturbances in a National Sample of U.S. Adults. J Trauma Stress. 2019;32(1):14-22. http://dx.doi. org/10.1002/jts.22360 www.ncbi.nlm.nih.gov/pubmed/30702778 11- Brown WJ, Wilkerson AK, Milanak ME, Tuerk PW, Uhde TW, 
Cortese BM, et al. An examination of sleep quality in veterans with a dual diagnosis of PTSD and severe mental illness. Psychiatry Res. 2017;247:15-20. http://dx.doi.org/10.1016/j. psychres.2016.07.062 www.ncbi.nlm.nih.gov/pubmed/27863313

12- Garcia JA, FC YO, Matheu ML, Carreno TP. Self esteem levels vs global scores on the Rosenberg self-esteem scale. Heliyon. 2019;5(3):e01378. http://dx.doi.org/10.1016/j.heliyon.2019. e01378 www.ncbi.nlm.nih.gov/pubmed/30963120

13- Feemster JC, Smith KL, McCarter SJ, St Louis EK. TraumaAssociated Sleep Disorder: A Posttraumatic Stress/REM Sleep Behavior Disorder Mash-Up? J Clin Sleep Med. 2019;15(2):3459. http://dx.doi.org/10.5664/jesm.7642 www.ncbi.nlm.nih.gov/ pubmed/30736880

14- Dedert EA, Dennis PA, Cunningham KC, Ulmer CS, Calhoun PS, Kimbrel N, et al. Roles of Guilt Cognitions in Trauma-Related Sleep Disturbance in Military Veterans With Posttraumatic Stress Disorder. Behav Sleep Med. 2019;17(5):595-604. http://dx.doi. org/10.1080/15402002.2018.1435544 www.ncbi.nlm.nih.gov/ pubmed/29482385

15- Mysliwiec V, Brock MS, Creamer JL, O’Reilly BM, Germain A, Roth BJ. Trauma associated sleep disorder: A parasomnia induced by trauma. Sleep Med Rev. 2018;37:94-104. http:// dx.doi.org/10.1016/j.smrv.2017.01.004 www.ncbi.nlm.nih.gov/ pubmed $/ 28363448$

16- Najjaran Toussi H, Shareh H. Changes in the Indices of Body Image Concern, Sexual Self-Esteem and Sexual Body Image in Females Undergoing Cosmetic Rhinoplasty: A Single-Group Trial. Aesthetic Plast Surg. 2019;43(3):771-9. http://dx.doi.org/10.1007/ s00266-019-01336-2 www.ncbi.nlm.nih.gov/pubmed/30805690

17- Hannier S, Baltus A, De Sutter P. The role of physical satisfaction in women's sexual self-esteem. Sexologies. 2018;27(4):e85-e95. http://dx.doi.org/10.1016/j.sexol.2017.09.010

18- Mota NP, Turner S, Taillieu T, Garces I, Magid K, Sethi J, et al. Trauma Exposure, DSM-5 Post-Traumatic Stress Disorder, and Sexual Risk Outcomes. Am J Prev Med. 2019;56(2):215-23. http://dx.doi.org/10.1016/j.amepre.2018.08.025 www.ncbi.nlm. nih.gov/pubmed/30553694

19- Pereira MG, Pereira D, Pedras S. PTSD, psychological morbidity and marital dissatisfaction in colonial war veterans. J Ment Health. 2019:1-8. http://dx.doi.org/10.1080/09638237.2018.1487532 www.ncbi.nlm.nih.gov/pubmed/30661427

20- Letica-Crepulja M, Stevanovic A, Protuder M, Popovic B, Salopek-Ziha D, Vondracek S. Predictors of Sexual Dysfunction in Veterans with Post-Traumatic Stress Disorder. J Clin Med. 2019;8(4). http://dx.doi.org/10.3390/jcm8040432 www.ncbi.nlm. nih.gov/pubmed/30934864

21- Smith PH, Potenza MN, Mazure CM, McKee SA, Park CL, Hoff RA. Compulsive sexual behavior among male military veterans: prevalence and associated clinical factors. J Behav Addict. 2014;3(4):214-22. http://dx.doi.org/10.1556/JBA.3.2014.4.2 www.ncbi.nlm.nih.gov/pubmed/25592306

22- Badour CL, Gros DF, Szafranski DD, Acierno R. Sexual Problems
Predict PTSD and Depression Symptom Change Among Male OEF/OIF Veterans Completing Exposure Therapy. Psychiatry. 2016;79(4):403-17. http://dx.doi.org/10.1080/00332747.2016.114 2774 www.ncbi.nlm.nih.gov/pubmed/27997327

23- Lahav Y, Price N, Crompton L, Laufer A, Solomon Z. Sexual satisfaction in spouses of ex-POWs: The role of PTSD symptoms and self-differentiation. J Sex \& Marital Therapy. 2019(justaccepted):1-32.

24- Larsen SE. Hypersexual Behavior as a Symptom of PTSD: Using Cognitive Processing Therapy in a Veteran with Military Sexual Trauma-Related PTSD. Arch Sex Behav. 2019;48(3):987-93. http://dx.doi.org/10.1007/s10508-018-1378-1 www.ncbi.nlm.nih. gov/pubmed/30783872

25- Seehuus M, Pigeon W. The sleep and sex survey: Relationships between sexual function and sleep. J Psychosom Res. 2018;112:5965. http://dx.doi.org/10.1016/j.jpsychores.2018.07.005 www.ncbi. nlm.nih.gov/pubmed/30097137

26- Delaware A. Research methods in psychology and educational sciences. Tehran 2016.

27- Buysse DJ, Reynolds CF, Monk TH, Berman SR, Kupfer DJ. The Pittsburgh sleep quality index: A new instrument for psychiatric practice and research. Psychiatry Research. 1989;28(2):193-213. http://dx.doi.org/10.1016/0165-1781(89)90047-4

28- Behboodi Moghadam Z, Keshavarz Afshar M, Pourrahimi A, Taghizadeh Z, Mokhtari Zanjani P, Montazeri A. Evaluation of Postpartum Sleep Quality and the Influential Factors in the Women in Zanjan City, Iran (2014). The Iranian Journal of Obstetrics, Gynecology and Infertility. 2018;21(1):6-14.

29- Rezapour Mirsaleh Y, Ahmadi K. Psychometric Characteristics of Secondary Trauma Questionnaire (STQ) in Warfare. Iranian J Psychiatry \& Clinical Psychology. 2017;23(3):348-61. http:// dx.doi.org/10.29252/nirp.ijpcp.23.3.348

30- Farokhi S, Shareh H. Psychometric Properties of the Persian Version of the Sexual Self-Esteem Index for Woman-Short Form Iran. J Psychiatry Clin Psychol. 2014;20(3):252-63. http://dx.doi. org/10.1037/t54661-000

31- Yahyazadeh H, Yahyazadeh N. Studding the Issues of Veteran's Wives Life. Social Development \& Welfare Planning. 2017;7(28):97-121.

32- Williams SG, Collen J, Orr N, Holley AB, Lettieri CJ. Sleep disorders in combat-related PTSD. Sleep Breath. 2015;19(1):17582. http://dx.doi.org/10.1007/s11325-014-0984-y www.ncbi.nlm. nih.gov/pubmed/24752303

33- Germain A. Sleep disturbances as the hallmark of PTSD: where are we now? Am J Psychiatry. 2013;170(4):372-82. http://dx.doi. org/10.1176/appi.ajp.2012.12040432 www.ncbi.nlm.nih.gov/ pubmed/23223954

34- El-Solh AA, Adamo D, Kufel T. Comorbid insomnia and sleep apnea in Veterans with post-traumatic stress disorder. Sleep Breath. 2018;22(1):23-31. http://dx.doi.org/10.1007/s11325-0171618-y www.ncbi.nlm.nih.gov/pubmed/29330769

35- Seidi PAM, Mohammadi H, Khazaie H, Abas NQ, Jaff D. 
Psychometric properties of the Kurdish version of Pittsburgh Sleep Quality Index. Sleep Med. 2019;63:75-81. http://dx.doi. org/10.1016/j.sleep.2019.04.022 Www.ncbi.nlm.nih.gov/ pubmed/31606652

36- Sopp MR, Brueckner AH, Schafer SK, Lass-Hennemann J, Michael T. REM theta activity predicts re-experiencing symptoms after exposure to a traumatic film. Sleep Med. 2019;54:142-52. http://dx.doi.org/10.1016/j.sleep.2018.10.030 www.ncbi.nlm.nih. gov/pubmed/30557840

37- Noghani ME. An Interactive Study of the Effect of Social Economic Status and Support on Life Quality and Mental Happiness of Veterans' Wives with Post-Traumatic Stress Disorder in Mashhad. J Military Med. 2017;19(3):274-81.

38- Choi KB, Jang SH, Lee MY, Kim KH. Sexual life and self-esteem in married elderly. Arch Gerontol Geriatr. 2011;53(1):e17-20. http://dx.doi.org/10.1016/j.archger.2010.08.011 www.ncbi.nlm. nih.gov/pubmed/20932589

39- Lordello MC, Ambrogini CC, Fanganiello AL, Embirucu TR, Zaneti MM, Veloso L, et al. Creation and Validation of the Self-
esteem/Self-image Female Sexuality (SESIFS) Questionnaire. Clin Med Insights Womens Health. 2014;7:37-43. http:// dx.doi.org/10.4137/CMWH.S19182 www.ncbi.nlm.nih.gov/ pubmed/25574149

40- Ramezani N, Dolatian M, Shams J, Alavi H. The relationship between self-esteem and sexual dysfunction and satisfaction in women. J Arak Univ Med Sci. 2012;14(6):57-65.

41- Sikka SC, Hellstrom WJ. Bioenvironmental issues affecting men's reproductive and sexual health: Academic Press; 2017.

42- Ahmadian C, Mirrezaie S, Nouhi S, Khastar H. Evaluating the Relationship Between Sleep Disturbances and Sexual Quality of Life Among Female Shift Working Nurses. J Knowledge Health. 2018;13(1):19-25.

43- Lee DM, Tetley J. Sleep quality, sleep duration and sexual health among older people: Findings from the English Longitudinal Study of Ageing. Arch Gerontol Geriatr. 2019;82:147-54. http:// dx.doi.org/10.1016/j.archger.2019.02.010 www.ncbi.nlm.nih.gov/ pubmed/30797993 